\title{
Redes solidárias de catadores e gestão de resíduos sólidos ${ }^{1}$
}

\author{
Solidarities networks of recyclable collectors and garbage management
}

\author{
Jacqueline E. Rutkowski²
}

\section{RESUMO}

A constituição de redes entre empreendimentos têm sido preconizadas como forma de ampliar as vantagens competitivas de empresas e a sustentabilidade dos empreendimentos econômicos solidários (EES), como no caso das cooperativas e associações de catadores (ACs) que são continuamente induzidas por meio de editais de fomento, a buscarem esta forma de organização. Porém, as peculiaridades dos EES os diferenciam da empresa tradicional e trazem determinados elementos para a implantação desta estratégia, com os quais as ACs têm crescentes dificuldades de lidar. A partir dos resultados de uma pesquisa-ação junto à Rede de Economia Solidária CATAUNIDOS e de pesquisas exploratórias desenvolvidas nos últimos5 anos junto a outras redes solidárias de catadores no Brasil, discute-se por que essas estratégias vêm sendo desenvolvidas e suas implicações na organização interna e nos resultados econômicos e sociais dos empreendimentos solidários. Percebe-se que apesar de aparentemente necessária e vantajosa, a construção de redes solidárias demanda esforços e recursos de várias ordens nem sempre disponíveis aos EES. Prescinde-se de conhecimento e tecnologias apropriadas, bem como da disponibilidade de recursos humanos, financeiros e de financiamentos acessíveis. Além de discutir algumas possíveis soluções para estas questões, discute-se também, as implicações desta estratégia para a concretização dos preceitos da Política Nacional de Resíduos Sólido, que sugere a inclusão dos catadores nos programas de gestão de resíduos sólidos urbanos.

Palavras-chave: Redes. Empreendimentos econômicos solidários. Catadores de materiais recicláveis. Pesquisa-ação. PNRS.

\begin{abstract}
The strategy of constitution of companies' nets has been used as form of enlarging their competitive advantages. Such strategies have also been used in the Solidary Economy, as form of enlarging the sustainability of the solidary economical enterprises (EES). In spite of seemingly to treat of similar strategies, the peculiarities of EES differentiate them of the traditional company and bring to them new elements for the constitution of these nets. Through a research-action close to the Rede de Economia Solidária CATAUNIDOS and other researches done in other nets is discussed as those strategies can be developed and their implications in the internal organization and in the results on these enterprises. It is noticed that in spite of good results, the construction of solidary nets demands efforts and resources of several orders not always available to EES. It is discussed also these implications to the new Brazilian politics of garbage management, that defends the inclusion of collectors cooperatives garbage in the services.
\end{abstract}

Keywords: Enterprise networks. Solidary economical enterprises. Collectors of recyclable materials. Research-action.

\footnotetext{
${ }^{1}$ Trabalho apresentado no dia 16 de outubro de 2013, no Grupo de Trabalho 8 - Tensões tecnológicas na cadeia produtiva do lixo.

${ }^{2}$ Doutora em Engenharia de Produção (COPPE/UFRJ); Pesquisadora e Diretora do Instituto SUSTENTAR Interdisciplinar de Estudos e Pesquisas em Sustentabilidade; Consultora nos temas: Sustentabilidade, Reciclagem de Resíduos Sólidos Urbanos, Metodologias Participativas e Economia Solidária. Email: jacqueline.rutkowski@gmail.com
} 


\section{APRESENTAÇÃO DO PROBLEMA E OBJETIVO DA PESQUISA}

Por meio de sua organização como movimento social, os catadores de materiais recicláveis têm conquistado alguns direitos, assegurados por meio de leis e políticas públicas. Dentre eles, e, talvez, o mais significativo, está a recomendação da participação dos empreendimentos solidários de catadores nos programas de gestão integrada dos resíduos sólidos urbanos.

A Lei 12.305/2010 - que define a Política Nacional de Resíduos Sólidos, prevê integrar os catadores na Coleta Seletiva e na Logística Reversa, por meio da estruturação de organizações (cooperativas e/ ou associações produtivas - ACs) a partir das quais se viabiliza a instalação de galpões e, ainda, a aquisição dos equipamentos necessários à realização de atividades que permitam reincluir materiais recicláveis retirados do lixo na cadeia produtiva da reciclagem de resíduos sólidos. A lei prevê, dentre outros, que o município que implantar a coleta seletiva com a participação de cooperativas/associações de catadores de baixa renda terão

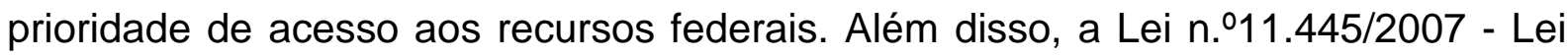
de Diretrizes Nacionais de Saneamento Básico (LDNSB) preconiza a dispensa de licitação para a contratação das organizações de catadores para prestar serviços de coleta, processamento e comercialização de resíduos sólidos urbanos recicláveis ou reutilizáveis.

Para atender a estas diretrizes tem-se sugerido a organização de redes de associações e cooperativas que se responsabilizariam por esta prestação de serviços. As razões que embasam esta proposta são:

1. Permitir maior abrangência territorial e garantir capilaridade e universalização da coleta seletiva em todo o município - sendo um serviço público, a coleta seletiva deveria estar disponível para todos os munícipes, e para garantir uma cobertura em $100 \%$ dos maiores municípios seria necessário um número elevado de catadores. Além disso, considerando os custos de transporte e a logística de coleta, a organização de centros regionais de triagem descentralizados se apresenta como mais eficaz. Esses fatores, associados à dificuldade de se organizar um grande número de catadores em uma única cooperativa ou associação ${ }^{3}$, desagua na

\footnotetext{
${ }^{3}$ Estudos diversos, tais como os de VAZOLLER, 2004; METELLO, 2007 e KASMIR, 2007, demonstram que quanto maior o empreendimento e quanto mais complexa a estrutura menos possível torna-se uma
} 
proposta de se organizar várias ACs, as quais formariam uma rede para a prestação do serviço. Para facilitar a relação com o Poder público muitas vezes indica-se a necessidade de se institucionalizar a rede, transformando-a em uma cooperativa de segundo grau formada com a associação das diversas ACs, pois isso significaria um único contrato a ser gerido, simplificando os processos e, possivelmente, reduzindo custos administrativos.

2. Ampliar a capacidade de gestão dos catadores - acredita-se que a organização dos catadores em rede permitiria a difusão de saberes e de boas práticas e experiências entre as organizações, aumentando a eficiência de todo o conjunto. Além disso, unidos estariam mais fortalecidos o que facilitaria o acesso a mais conhecimento, por meio de assistência técnica;

3. Ampliar a capacidade de operação: a rede disporia de um maior número de equipamentos e de pessoal, o que significaria, também, mais facilidade de acesso a editais de fomento e a fontes de financiamento;

4. Permitir a incorporação de mais catadores e particularmente dos catadores avulsos, que muitas vezes não se adequam ao trabalho no galpão de triagem, mas que poderiam ser incorporados na logística de coleta porta a porta, entregando os materiais que recolhessem não mais a um atravessador, mas a uma associação ou cooperativa, com quem manteria relações solidárias. Isto significaria, por exemplo, compartilhar ganhos de preços obtidos devido à escala de comercialização, usos de espaços nos galpões para banhos, refeições e descanso já que muitas vezes estes são moradores de rua, facilidade de acesso a políticas de assistência social e de saúde, etc. Isto seria particularmente importante considerando que uma das diretrizes estabelecidas pelo Plano Nacional de Resíduos Sólidos é a inclusão e organização de 600.000 catadores de materiais reutilizáveis e recicláveis;

5. Reduzir custos da Coleta Seletiva e ampliar a capacidade de geração de trabalho e renda por meio dos resíduos sólidos urbanos- a ampliação do número de catadores envolvidos permitiria o uso de transporte multimodais (recolhimento do material por meio de carrinhos com tração humana ou a motor até um local onde

participação direta dos produtores associados. Por isso, percebe-se que, em geral, melhores resultados são obtidos em empreendimentos de menor porte onde as características da gestão social são mais factíveis de serem implementadas. 
estes seriam recolhidos por caminhão, após atingir determinada quantidade), reduzindo sobremaneira o custo com transporte, e permitindo a otimização de recursos, o que facilitaria garantir a perenidade do Programa de Coleta Seletiva que em geral, deixa de ser ampliado pelas Prefeituras devido ao alto custo.

Outra razão sempre lembrada para a organização dos catadores em rede é a possibilidade de ocupar um lugar considerado estratégico na cadeia produtiva da reciclagem, o de fornecedor da indústria de reciclagem. Por meio da organização em rede os catadores poderiam formar escala suficiente para comercializar diretamente com a indústria de papel, por exemplo, tal como um aparista, obtendo maiores preços no material em função da capacidade de atender à escala e aos requisitos de qualidade, critérios dificilmente atingíveis por uma organização isoladamente. Ou, até mesmo, organizar empreendimentos industriais para beneficiamento de plástico, ou de resíduo eletroeletrônico.

Assim, tal forma de organização vem paulatinamente sendo imposta aos catadores, como demonstra os objetivos e critérios de análise dos últimos editais de fomento disponibilizados pelo Governo Federal (vide projetos Cataforte I, II, regras de acesso ao Fundo Social do BNDES e a recursos de patrocínio da Petrobrás). A ideia é a da profissionalização da ação dos catadores, como prestadores de serviços e até mesmo como atores empresariais da cadeia produtiva da reciclagem de resíduos sólidos.

Para os catadores a organização em redes é percebida como uma forma de "fortalecer o catador", uma vez que em rede sentem-se com mais poder de negociação com o Poder Público, com os compradores e os grandes geradores de materiais recicláveis. $E$ também com mais facilidade para atender as formalidades de editais de fomento e as do mercado, tais como emitir Nota Fiscal.

Entretanto, se a constituição de redes entre empresas tem sido cada vez mais utilizada como forma de ampliar as vantagens competitivas, isto não tem se dado sem dificuldades. Geralmente as empresas se associam para atender a necessidades que dificilmente poderiam viabilizar de maneira individual, tais como exercer uma força maior no mercado ou partilhar riscos e custos de explorar novas oportunidades. Em busca destes objetivos organizam-se cadeias de suprimentos e até mesmo ocorrem fusões e aquisições, onde, em geral, uma empresa líder amplia suas vantagens impondo a empresas menores condições e formas de 
relacionamento que acabam por se traduzir na apropriação de conhecimentos, e até mesmo de parcelas do lucro destas, pela redistribuição de custos, por exemplo.

Considerando estes fatos e as especificidades dos empreendimentos econômicos solidários face às empresas, iniciamos uma reflexão a respeito das consequências da aplicação desta proposta nas organizações dos catadores. Quais seriam as dificuldades da aplicação desta estratégia nestas organizações? De que maneira tal estratégia impacta a sustentabilidade das ACs e a inclusão social e econômica de catadores? A forma como buscamos responder às estas questões e os resultados obtidos estão relatados na seção seguinte.

\section{MÉTODOS E RESULTADOS DA PESQUISA}

Dois métodos foram utilizados na pesquisa. Inicialmente estruturou-se uma pesquisa-ação junto a uma rede de economia solidária - a Rede CATAUNIDOS, que iniciou sua formação no ano de 2002, em Minas Gerais, em torno da ASMARE, uma das primeiras associações de catadores formadas no Brasil, ainda no início da década de 1990. Após 4 anos de periódicas reuniões e atividades conjuntas de lutas, capacitação e discussões envolvendo os catadores das nove associações e cooperativas que a constituíram ${ }^{4}$, foi oficializada a Cooperativa de Reciclagem dos Catadores da Rede de Economia Solidária - CATAUNIDOS. Na época a Rede já havia obtido apoio para a implantação de uma fábrica, instalada no ano de 2005 com capacidade para processar todo o plástico coletado pelas organizações, de forma a agregar valor ao material e eliminar a figura do atravessador na comercialização do plástico. Posteriormente, a Rede começou também a organizar a comercialização conjunta de outros materiais tais como o papel e o papelão, tendo sempre como objetivo esperado o aumento da renda final de cada catador associado.

Durante todo esse processo manteve-se uma dinâmica de reuniões quinzenais de representantes de cada uma das associações/ cooperativas e representantes das respectivas prefeituras municipais para, sob a coordenação de técnicos do INSEA, discutir a situação de cada uma das ACs, da central de

\footnotetext{
4 Todo essa articulação contou com o apoio de técnicos do INSEA, ONG que se formou a partir dos militantes da Pastoral de Rua que ajudaram a construir a ASMARE.
} 
comercialização e da fábrica. A pesquisa-ação realizada utilizou como seminário central para discussão e deliberação de pesquisa essas reuniões. Além disso, outras técnicas participativas de levantamento e discussão de dados foram empregadas neste período ${ }^{5}$.

A partir deste estudo, iniciou-se um trabalho de observação participante e de organização e sistematização de dados obtidos por meio de trabalhos de consultoria contratados por instituições de fomento aos catadores, que vêm sendo realizados desde o ano de 2008. Além de visitas técnicas a ACs nas várias regiões do Brasil, com realização de entrevistas semiestruturadas com informantes chaves nas instituições, foram realizadas, oficinas de diagnóstico e planejamento participativos com catadores e técnicos de apoio, dentre outras técnicas de registro e levantamento de dados.

Por meio deste levantamento elencamos as dificuldades identificadas pelos catadores para construir e gerir suas redes em três grandes blocos:

\subsection{VENCER A COMPLEXIDADE QUE CONSTRUIR E TRABALHAR EM REDE TRAZ}

Montar e tocar uma rede significa lidar com questões de várias ordens e que demandam tempo e pessoas disponíveis e com capacidade para construir as diversas atividades e articulações necessárias para o enredamento das instituições. Raramente os projetos de fomento que induzem a formação destas redes dispõem de tempo suficiente para que este processo ocorra. E quase nunca disponibilizam recursos financeiros para que profissionais de apoio possam ser contratados, no tempo adequado.

Isso se agrava com a falta de maturidade em torno da ideia do trabalho compartilhado entre organizações e de visão coletiva, ou seja, da compreensão dos reais objetivos e vantagens que a organização em rede poderia proporcionar e de seus impactos nos interesses individuais de cada organização e, mesmo, de cada

\footnotetext{
5 Esta pesquisa está detalhada em RUTKOWSKI, J.E. Sustentabilidade de Empreendimentos Econômicos Solidários: uma abordagem na Engenharia de Produção. 2008. 239f. Tese (Doutorado em Engenharia de Produção). COPPE, Universidade Federal do Rio de Janeiro, Rio de Janeiro, RJ, 2008.
} 
catador. Há muita dificuldade de levar o assunto à discussão junto as chamadas "bases" (catadores associados). O dia a dia das ACs raramente permite momentos de reflexão coletiva e, em muitas delas, faltam mecanismos para, de fato, fazer as informações fluírem entre todos. Tudo isso impacta negativamente a possibilidade de se construir metas comuns a partir das imprescindíveis relações de confiança entre empreendimentos, seus gestores e associados.

Da mesma maneira, raramente existem mecanismos eficientes de tomada de decisão coletiva na rede. E de troca de experiências entre as ACs, que permitam aprender com erros e acertos. Ou seja, gerenciar uma rede demanda determinados instrumentos e expertises. Nas redes empresariais, uma empresa, além de liderar todo o processo, fornece todos estes quesitos por meio de seus profissionais e infraestrutura, ou contratando consultoria especializada para tal. Por outro lado, exerce o controle e poder de decisão sobre a rede, situação supostamente a ser evitada em uma rede solidária.

\subsection{SOLUCIONAR QUESTÕES OPERACIONAIS DIVERSAS NECESSÁRIAS AO BOM DESEMPENHO FINANCEIRO DA REDE}

Há, ainda muita fragilidade na infraestrutura da maioria das ACs e, é comum em uma mesma rede observar-se um grande desnível em termos de equipamentos, estruturação dos galpões, e experiência entre elas. A falta de coleta seletiva na maioria dos municípios brasileiros também impede um maior aumento de produtividade nos galpões. Assim, obter a escala de produção de recicláveis na regularidade necessária para atender à comercialização conjunta e o fornecimento à indústria exige acertos nas organizações individualmente. Exige, também, padronização de qualidade dos materiais e de controles e ferramentas de gestão, o que, por sua vez, implicaria na padronização dos processos de trabalho nos diferentes galpões. Esta padronização é o objetivo buscado nas empresas por meio da implantação de sistemas de gestão da qualidade, tais como ISO 9000, Qualidade Total, etc. Além da inadequação da aplicação destas ferramentas nas ACs, a padronização é dificultada pela existência de diferenças significativas entre os grupos de catadores - características físicas e pessoais, formas de remuneração 
praticadas, infraestrutura, etc. e entre os resíduos gerados e o tipo de coleta praticado, fatores que impactam a qualidade e a quantidade dos recicláveis obtidos.

Muitas vezes, obter escala implica em estocar material por um determinado tempo, e para isso é necessário espaço de estocagem, seja na cooperativa/ associação de origem ou em um galpão coletivo. Há também outros custos associados tais como o de transporte, de pessoal, administrativo, seguros, licenciamentos, etc. Assim, estocar material implica na necessidade de capital de giro para fazer frente às despesas operacionais, até que o material estocado seja comercializado e que o valor faturado seja recebido, pois este pagamento não é imediato. É fartamente reconhecida a dificuldade de acesso dos empreendimentos econômicos solidários a fontes de financiamento de capital de giro. Resta-lhes, então, dispor de parte das retiradas dos associados para fazer frente a estes custos. Com isso, ao invés de ampliar a renda conforme objetivado a partir da implementação da Rede, muitos catadores vêm sua renda diminuída... Isso se agrava ainda mais quando se observa que nenhuma das redes pesquisadas passou por um processo estruturado de planejamento e nem teve acesso a Estudos de Viabilidade Técnica e Econômica ou construiu um Plano de Negócios da Rede, de modo a deixar claro aos catadores as necessidades financeiras e prazos associados a este investimento.

\subsection{COMPREENDER E ATUAR ESTRATEGICAMENTE NO MERCADO DA RECICLAGEM}

Há de início, a identificação de um problema que é comum a todos os EES: a falta de legislação de apoio ao cooperativismo popular torna mais complexa a formalização das Redes ${ }^{6}$, aumenta os custos de tributos e os tempos de licenciamentos, dificulta acesso a fontes de financiamento, dentre outras inúmeras

\footnotetext{
${ }^{6}$ Para exemplificar: o registro da CATAUNIDOS na Junta Comercial de MG demandou vários meses, pois não havia jurisprudência em relação a uma cooperativa de segundo grau cujos cooperados fossem ao mesmo tempo, pessoas físicas (catadores) e jurídicas (suas associações). Há desconhecimento da maioria dos contadores sobre os tributos realmente devidos por estes empreendimentos e sobre seus direitos de comercializar materiais e prestar serviços. Muitas vezes o Judiciário entende ser necessário às ACs atender à legislação trabalhista, cujas regras foram definidas para garantir direitos dentro de uma relação patrão/empregado e não dentre trabalhadores associados, etc.
} 
questões que acabam por impedir que se firmem contratos de fornecimento de matéria prima com a indústria da reciclagem e lou de prestação de serviços com Prefeituras. Agrava esta situação a inexistência de tecnologias apropriadas para um empreendimento econômico solidário dominar as estratégias mais avançadas de atuação no mercado. Cada passo dado em direção ao topo da cadeia produtiva significa lidar com mais tecnologia e informação. Significa também atuar em meio a número menor de competidores, muito mais competitivos. O que implica, então, em se dominar tecnologias de produção e gestão e conhecimentos muito mais sofisticados e mais difíceis de obter-se e de se lidar. Falta escolaridade aos catadores, e falta, principalmente, assistência técnica adequada para fornecer-lhes apoio nestas questões.

Há, também, questões inerentes ao mercado da reciclagem. O domínio que os atravessadores (grande aparistas e depósitos) têm, ainda, na comercialização de recicláveis, a incapacidade tecnológica e econômica de reciclar parte dos materiais recicláveis hoje disponíveis dentre os resíduos sólidos urbanos e a falta de um marco regulatório para a reciclagem no Brasil, que induza um maior uso de matéria prima reciclada na indústria, diminuem as possibilidades de ganhos destas Redes e levam a se questionar sobre sua viabilidade técnica e econômica a partir unicamente de ganhos obtidos no mercado de recicláveis. ${ }^{7}$

\section{CONCLUSÕES}

O diagnóstico apresenta problemas de diversos tipos e que impactam diretamente a concretização da inclusão dos catadores na gestão dos resíduos sólidos urbanos, tal como definido no marco legal vigente. Como ampliar o número de catadores, se a renda unitária diminui? Como assinar contratos de prestação de serviços com o Poder público sem garantia de realização do sérvio na qualidade, regularidade e eficiência demandada? Grande parte destes problemas se originam da falta de garantias técnico-político-institucionais para as alternativas de trabalho, renda e auto emprego, organizadas sob a ótica da Economia Popular e Solidária no

\footnotetext{
7 Sobre estas e outra s questões ver: Rutkowski, J. E. et al, Análise da cadeia produtiva dos materiais recicláveis no Brasil.2013. 243f. Relatório de Pesquisa. Instituto SUSTENTAR/ FBB, Brasília/DF,2013.
} 
Brasil. Dialogando com o mercado e com a economia capitalista para vender seus produtos e prestar seus serviços ${ }^{8}$, estes empreendimentos são tratados por estes da mesma forma que os circuitos informais da economia, e vivem o desafio de gerar por conta própria, e de maneira solidária, as relações comerciais, sociotécnicas e culturais necessárias a este diálogo.

Entretanto, se se deseja concretizar a participação das organizações de catadores na PNRS demandam-se soluções para os problemas apontados. As redes de catadores vêm sendo construídas, cada vez mais, com autonomia e desenvoltura pelos catadores que, paulatinamente assumem a coordenação e a iniciativa na proposição de soluções para seus problemas. Entretanto, esta construção e o fortalecimento das redes solidárias dependem ainda de um tipo de conhecimento que não está devidamente estabelecido e disseminado.

Constituir as redes de ACs demanda o estabelecimento de formas de animação, comunicação e decisão adequadas à criação de diálogo e interação entre os atores, e construídas segundo uma ética cooperativa que precisa também ser continuamente construída. É necessário permitir aos empreendimentos atuar segundo uma tática de empresa, mas como uma estratégia de movimento, em que a responsabilidade de cada um com os resultados coletivos possa ser estabelecida a partir da definição de um mínimo moral comum e de ações dirigidas a fins préestabelecidos.

Ou seja, não se trata somente de se estabelecer metas e indicadores a serem avaliados a partir de relações custo $X$ benefício em que o benefício é meramente econômico, mas, também de se definir valores que embasarão estas metas e as formas de obtê-las, para que respondam, também, aos objetivos de inclusão social, de melhoria de condições de trabalho e de renda e dos resultados ambientais esperados a partir da implantação da PNRS, tal como ela foi definida.

Construir estas soluções depende de se reconhecer uma capacidade de planejamento nos trabalhadores, e a necessidade de implicá-los diretamente neste planejamento, embora possa parecer, às vezes, que os objetivos destes nem sempre sejam os mesmos dos empreendimentos e os tempos e métricas sejam completamente diferentes. Em uma rede solidária é sempre mais perene uma

\footnotetext{
${ }^{8}$ Embora aqui se trate de serviços públicos, é inegável que o Poder público se referencia nas práticas capitalistas para definir seu modus operandi.
} 
descoberta feita em conjunto após vários erros e acertos coletivos, do que uma decisão considerada mais eficiente, definida de cima pra baixo. Ou seja, é necessário um diálogo efetivo entre o saber técnico e o saber prático e tácito, para descontruir e reconstruir soluções para os gargalos que se apresentam.

Esta premissa deve nortear a Assistência Técnica (ASTEC) a ser oferecida quando da construção destas Redes. Realizada por meio de metodologias de pesquisa e de consultoria participativas que permitam a inclusão de outros atores e seus saberes nestes processos, esta ASTEC precisa ser pensada a partir de métodos que garantam uma "orquestração das ciências" ${ }^{2}$ com os achados de diferentes áreas de conhecimento sendo coordenados e as contradições e incompatibilidades apontadas, a fim de serem dialeticamente combinadas na busca de soluções interdisciplinares.

Para isso é necessário que as Redes possam acessar profissionais das áreas de gestão de empreendimentos e de tratamento de resíduos sólidos críticos do conhecimento que utilizam e criam e da aplicação que dão a este conhecimento. Profissionais que sejam capazes de abandonar a gestão estratégica, que se implementa através da interação de pessoas exercendo autoridade formal uma sobre as outras, para agir como mediadores de processos participativos de diagnóstico e planejamento, nos quais a linguagem é fonte de integração social, permitindo que a implicação de atores se construa a partir de relações horizontais e afetivas e não como um meio para transmitir informações. Essa tarefa demandará, sem dúvida, modificar conceitos, reconstruir teorias e revolucionar práticas. E, também recursos financeiros e tempo. Resta saber em que medida tudo isto estará disponível...

\section{REFERÊNCIAS}

BOURDIEU, Pierre. Razões Práticas - sobre a teoria da ação. SP: Papirus Editora. 1997. 283p.

BRAVERMAN, Harry. Trabalho e capital monopolista - a degradação do

trabalho no século XX. RJ: Zahar Editores.1981. 379p.

\footnotetext{
${ }^{9}$ Conceito definido em MARTINEZ-ALIER, 1999.
} 
DESROCHE, H. Sobre o projeto cooperativo: democracia, animação e ética. In: THIOLLENT, M. (org.) Pesquisa-ação e projeto cooperativo na perspectiva de Henri Desroche. São Carlos, SP: Ed. UFSCar, 2006. p.131-154.

KASMIR, Sharryn. O Modelo Mondragón como discurso pós-fordista. In: LIMA, Jacob Carlos (org.). Ligações Perigosas -Trabalho Flexível e Trabalho Associado. São Paulo: Annablume, 2007. p.55-92.

MARTINEZ -ALIER, J. The Socio-ecological Embeddedness of Economic Activity: The Emergence of a Transdisciplinary Field. In: Sustainability and the social sciences. Becker, E. \& Jahn, T. (eds.). UNESCO/ ISOE. Zed Books. London. 1999.p.112-139

METELLO, Daniela G. Os Benefícios da Associação em Cadeias Produtivas Solidárias: O Caso da Justa Trama - Cadeia Solidária do Algodão Agroecológico. 2007. 156f. Dissertação (Mestrado em Engenharia de Produção). COPPE, Universidade Federal do Rio de Janeiro, Rio de Janeiro/RJ, 2007.

RAMOS, Alberto Guerreiro. A nova ciência das organizações: uma reconceitualização da riqueza das nações. 2. ed. Rio de Janeiro: Editora da FGV, 1989.

Rutkowski, J. E. et al. Análise da cadeia produtiva dos materiais recicláveis no Brasil. 2013. 243f. Relatório de Pesquisa. Instituto SUSTENTAR/ FBB, Brasília/DF, 2013.

RUTKOWSKI, J.E. Sustentabilidade de Empreendimentos Econômicos Solidários: uma abordagem na Engenharia de Produção. 2008. 239f. Tese (Doutorado em Engenharia de Produção). COPPE, Universidade Federal do Rio de Janeiro, Rio de Janeiro, RJ, 2008.

RUTKOWSKI, Jacqueline E. Rede de tecnologias sociais: pode a tecnologia proporcionar desenvolvimento social? In: LIANZA, S. \& ADDOR, F.(orgs.) Tecnologia e desenvolvimento social e solidário. Porto Alegre: Editora da UFRGS. 2005

RUTKOWSKI, Jacqueline E. \& LIANZA, Sidney. Sustentabilidade de empreendimentos solidários: que papel espera-se da tecnologia? In: FUNDAÇÃO

BANCO DO BRASIL. Tecnologia social: uma estratégia para o desenvolvimento. Rio de Janeiro: 2004, p. 167-186.

SANTOS, Boaventura de Souza. Produzir para viver - os caminhos da produção não capitalista. Rio de Janeiro, Ed. Civilização Brasileira, 2002, p. 475- 512.

VAZZOLER, Márcia Regina. Cooperativismo em assentamentos de reforma agrária: a sobrevivência de cooperativas do MST no contexto capitalista. 2004. 276f. Tese (Doutorado em Engenharia de Produção). Centro de Ciências Exatas e de Tecnologia, Universidade Federal de São Carlos, São Carlos/ SP, 2004. 